\title{
Binding Cellulose and Chitosan via Intermolecular Inclusion Interaction: Synthesis and Characterisation of Gel
}

\author{
Jiufang Duan, ${ }^{1}$ Chunrui Han, ${ }^{1}$ Liujun Liu, ${ }^{1}$ Jianxin Jiang, ${ }^{1}$ Jianzhang Li, ${ }^{1}$ \\ Yiqiang $\mathrm{Li}^{2}{ }^{2}$ and Chao $\mathrm{Guan}^{2}$ \\ ${ }^{1}$ Institute of Material Science and Technology, Beijing Forestry University, Beijing 100083, China \\ ${ }^{2}$ Beijing Shoufa Tianren Ecological Landscape Co.,Ltd., Beijing 102600, China
}

Correspondence should be addressed to Jiufang Duan; duanjiu99@163.com

Received 28 April 2014; Revised 29 September 2014; Accepted 30 September 2014

Academic Editor: Wen Zeng

Copyright (C) 2015 Jiufang Duan et al. This is an open access article distributed under the Creative Commons Attribution License, which permits unrestricted use, distribution, and reproduction in any medium, provided the original work is properly cited.

A novel cellulose-chitosan gel was successfully prepared in three steps: (1) ferrocene- (Fc-) cellulose with degrees of substitution (DS) of $0.5 \mathrm{wt} \%$ was synthesised by ferrocenecarboxylic acid and cellulose within dimethylacetamide/lithium chloride (DMAc/LiCl); (2) the $\beta$-cyclodextrin $(\beta$-CD) groups were introduced onto the chitosan chains by reacting chitosan with epichlorohydrin in dimethyl sulphoxide and a DS of $0.35 \mathrm{wt} \%$; (3) thus, the cellulose-chitosan gel was obtained via an intermolecular inclusion interaction of Fccellulose and $\beta$-CD-chitosan in $\mathrm{DMA} / \mathrm{LiCl}$, that is, by an intermolecular inclusion interaction, between the $\mathrm{Fc}$ groups of cellulose and the $\beta$-CD groups on the chitosan backbone at room temperature. The successful synthesis of Fc-cellulose and $\beta$-CD-chitosan was characterised by ${ }^{13} \mathrm{C}$-NMR spectroscopy. The gel based on $\beta$-CD-chitosan and Fc-cellulose was formed under mild conditions which can engender autonomous healing between cut surfaces after 24 hours: the gel cannot self-heal while the cut surfaces were coated with a solution of a competitive guest (adamantane acid). The cellulose-chitosan complex made by this method underwent self-healing. Therefore, this study provided a novel method of expanding the application of chitosan by binding it with another polymer.

\section{Introduction}

Chitosan is a partially deacetylated polymer of $\mathrm{N}$-acetyl glucosamine. It is essentially a natural, water-soluble derivative of cellulose with unique properties [1]. Chitosan is usually prepared from chitin and chitin has been found in a wide range of natural sources [2] (crustaceans, fungi, insects, annelids, molluscs, coelenterate, etc.) $[1,2]$. Chitosan is used in many applications (flocculant [3,4], clarifier [5-7], fibre [8,9], film $[10-12]$, and wound healing promoting agent $[13,14]$ ). Cellulose and chitosan have similar molecular structures, with the same b-glycoside linkages. The main difference is the presence of primary amino groups at the C-2 positions in chitosan, where cellulose has hydroxyl groups. The presence of active groups in chitosan's molecular structure allows for easy chemical modification. Cellulose and chitosan are both biocompatible, nontoxic, and naturally occurring biopolymers that have been used extensively for biomedical applications.
In recent years, many studies of the different applications of chitosan and especially of chitosan blends with cellulose have been undertaken [3-24]. The complex based on cellulose and chitosan is to be studied as a fibre $[8,9]$, a film $[3,8,10-$ $12]$, hydrogen $[7,15]$, and microspheres $[5,16,17]$ and be used as a drug carrier $[17,18]$, wound healing promoting agent $[14$, 15], a medical material [17], a food packaging material [11], an adsorbent [3-7], and as a range of other functional materials $[15,20-23]$. The preparation of cellulose-chitosan composite materials has involved two main strategies: physical mixing $[6,8,13]$ and covalent bonding $[24,25]$, whereas cellulosechitosan hydrogel binding with host-guest interactions has never been reported before. This method differed with physical mixing in that it incorporated a "lock" formed by the $\mathrm{Fc}$ and $\beta$-CD groups between cellulose and chitosan molecules: the gel prepared by this method with Fc-cellulose and $\beta$-CD-chitosan by self-assembled $\mathrm{Fc}$ and $\beta$-CD groups in the absence of chemical cross-links was also novel. The incorporation of "locks" ensured a uniform mixing system and the 


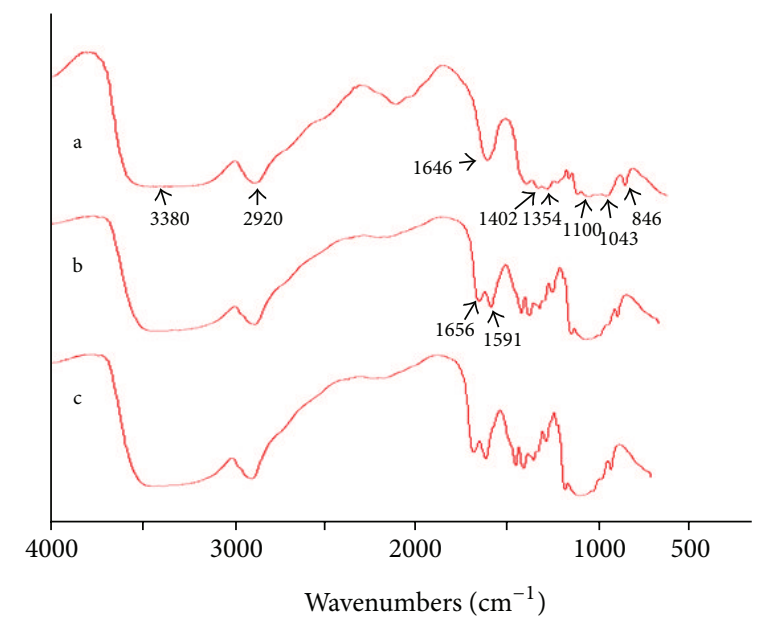

FIGURE 1: Infrared spectra of cellulose-Fc (a), chitosan-CDs (b), and the inclusion compound (c).

"locks" in this Fc- $\beta$-CD system made the materials smart in such a manner as to allow them to respond by their "locking" and "unlocking" behaviour [26-29]. The potential responsive properties present this kind of gel with a wider range of applications. The aim of this research was to modify the cellulose and chitosan and to prepare an Fc-cellulose/ $\beta$-CDchitosan gel.

\section{Experimental}

2.1. Materials. Cellulose (DP380), chitosan (DP465), $\beta$ cyclodextrin, epichlorohydrin, sodium hydroxide, lithium chloride, N,N-dimethyl acetamide, methylene chloride, ferrocene carboxylic acid, oxalyl chloride, sodium hypochlorite, and glutathione were commercially available and used as received. IR spectra were recorded by FTIR (Nicolet iN10 Thermo Fisher Scientific, China) in the region of 400 to $4000 \mathrm{~cm}^{-1}$. Compressive strengths were measured using an Instron 3365 Universal Testing Machine (Norwood, MA, USA) with the following parameters: sampling rate, 10.000 points/s; beam speed, $1.0000 \mathrm{~mm} / \mathrm{min}$; full-scale load range, $0.1000 \mathrm{kN}$; humidity, $25 \%$; and temperature, $23^{\circ} \mathrm{C}$. The gel samples were formed using a $10 \mathrm{~mm}$ diameter cylindrical die.

\subsection{Preparation of Cellulose-Chitosan Gel}

2.2.1. Preparation of Chitosan-CDs. $\beta-\mathrm{CD}$ and isopropanol were dissolved in dimethyl sulphoxide (DMSO). To this solution, epichlorohydrin and solution $(1 \mathrm{~mol} / \mathrm{L})$ were added. After stirring for $5 \mathrm{~h}$, chitosan was added and the solution was stirred for another $12 \mathrm{~h}$ at room temperature. The polymer product was reprecipitated from distilled water and washed with distilled water. The cyclodextrin grafting efficiency was $0.35 \% \mathrm{wt}$, which was detected by the phenolphthalein probe method [30].

2.2.2. Synthesis of $\mathrm{Fc}$-COCl. Ferrocenecarboxylic acid was suspended in dichloromethane (DCM). Then oxalyl chloride was added dropwise, and the suspension was stirred for $3 \mathrm{~h}$ at room temperature. The orange suspension turned into a red solution. After evaporating the solvent, the solid product was collected.

2.2.3. Synthesis of Cellulose-Fc. Cellulose was dissolved in lithium chloride/dimethylacetamide ( $\mathrm{LiCl} / \mathrm{DMAc})$. The chlorocarbonyl ferrocene solution was added dropwise. After stirring overnight at room temperature, the solution was washed with distilled water. The orange solid was washed with lithium chloride; the solid product was collected by centrifugation and dried for 4 days at $50^{\circ} \mathrm{C}$ to obtain the cellulose- $\mathrm{Fc}$ as a yellow powder. The ferrocene grafting rate was $0.5 \% \mathrm{wt}$, which was detected by weighing before and after the cellulose reaction.

2.2.4. Synthesis of Cellulose-Chitosan Gel. The ferrocenecellulose $(0.017 \mathrm{mM})$ and cyclodextrin-chitosan $(0.017 \mathrm{mM})$ were dissolved in $\mathrm{N}, \mathrm{N}$-dimethylformamide (DMF)/lithium chloride solution. The solution was poured into a glass mould in a humid box until the gel had stabilised.

\section{Results and Discussion}

Figure 1 shows the infrared spectra of the cellulose-Fc (a) and chitosan-CDs (b). According to the curves in (a), absorption was observed at $3380 \mathrm{~cm}^{-1}$ (hydroxyl stretch influenced by hydrogen bonding), $1646 \mathrm{~cm}^{-1}$ and $1354 \mathrm{~cm}^{-1}$ (carbonyl stretch), $1043 \mathrm{~cm}^{-1}$ (carboxyl in ethers), and $2920 \mathrm{~cm}^{-1}$ (methylene). The characteristic peaks of ferrocene could be found at $1402 \mathrm{~cm}^{-1}, 1100 \mathrm{~cm}^{-1}$ VC-C (cyclopentadienyl ring), and $856 \mathrm{~cm}^{-1} \mathrm{DC}-\mathrm{H}$ (cyclopentadienyl ring). As seen from the curves in (b), the characteristic absorption peaks of chitosan-CDs structures were observed at $1656 \mathrm{~cm}^{-1}$ (the stretching vibration of $\mathrm{C}=\mathrm{O}$ ) and at $1591 \mathrm{~cm}^{-1}$ (the bending vibration of $\mathrm{N}-\mathrm{H}$ ). The characteristic peaks of ferrocene disappeared from the infrared spectra of the envelope of the 


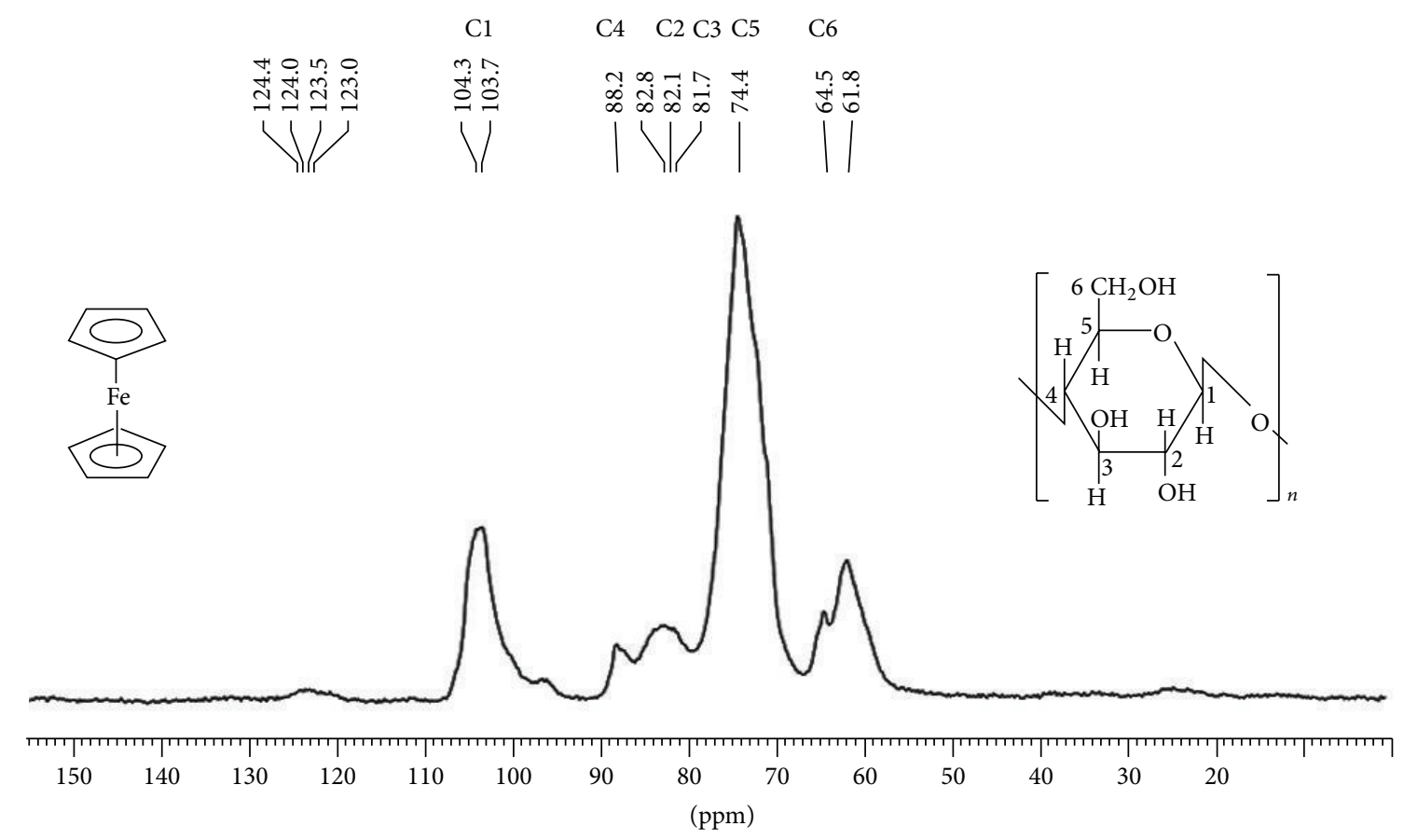

FIGURE $2:{ }^{13} \mathrm{C}$-NMR of cellulose-Fc.

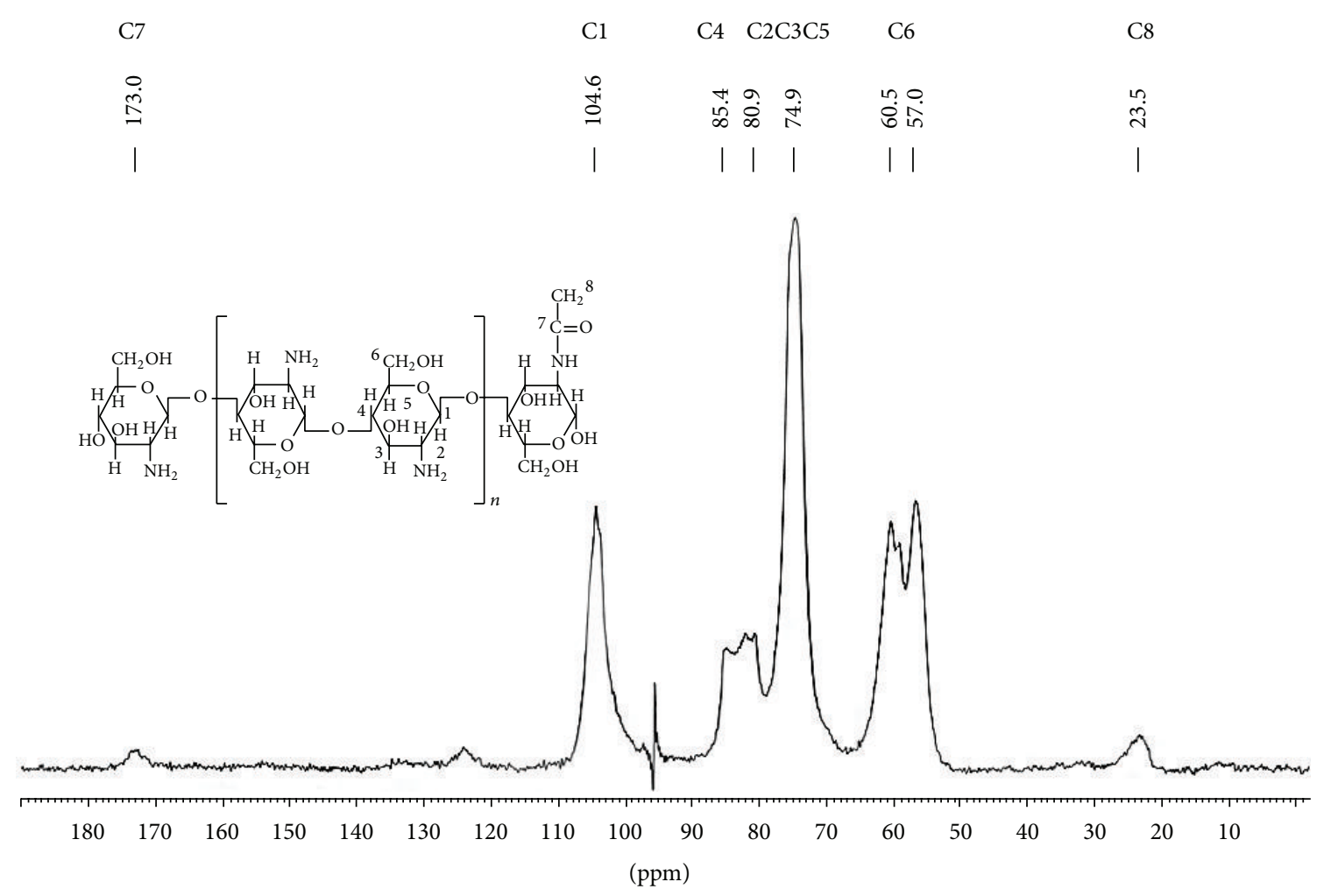

Figure $3:{ }^{13} \mathrm{C}-\mathrm{NMR}$ of chitosan-CDs. 


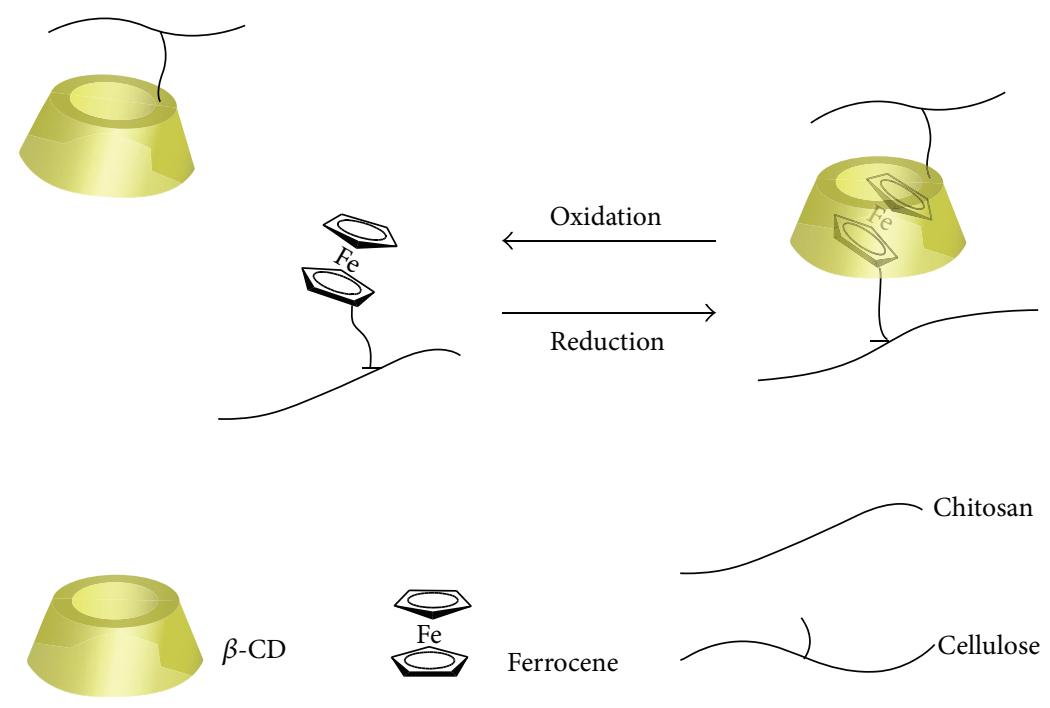

FIGURE 4: Intermolecular inclusion interaction of cellulose-chitosan hydrogel.

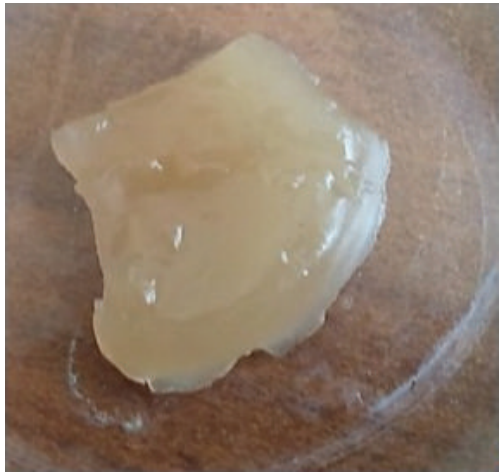

(a)

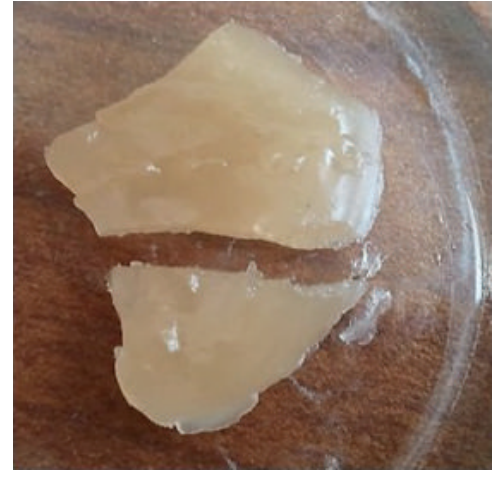

(b)



(c)

FIGURE 5: Self-healing experiments.

inclusion compound (curves in (c)). This indicated that the cellulose-Fc and chitosan-CDs have been formed in the inclusion complex. Similar findings were reported in the literature [26-28].

Figures 2 and 3 show the solid-state ${ }^{13} \mathrm{C}$-NMR spectra of the chitin-CDs and cellulose-Fc. As can be seen in Figure 2, the $\mathrm{C} 1$ of the glucose units was assigned to 104.3 and $103.7 \mathrm{ppm}$, their C4 was assigned to $88.2 \mathrm{ppm}, \mathrm{C} 2, \mathrm{C} 3$, and C5 were assigned to $74.4 \mathrm{ppm}$, and C6 was assigned to $61.8 \mathrm{ppm}$. Fc could be found at carbon sites in regions between 124.4 and $123.0 \mathrm{ppm}$ and 82.8 and $81.7 \mathrm{ppm}$; this suggested that ferrocene was successfully grafted to the cellulose by the proposed experimental method. A detailed assignment of different carbons of chitin-CDs was shown in Figure 3: the $\mathrm{C} 1$ site of the glucose units was assigned to $104.6 \mathrm{ppm}, \mathrm{C} 4$ to $85.4 \mathrm{ppm}, \mathrm{C} 2, \mathrm{C} 3$, and C5 to $74.9 \mathrm{ppm}, \mathrm{C} 6$ to $60.5 \mathrm{ppm}$ and $57.0 \mathrm{ppm}$, carbonyl carbon C7 (connected acetyl group) to $173.0 \mathrm{ppm}$, and C8 to $23.5 \mathrm{ppm}$. The carbon atoms connecting cellulose and cyclodextrin were assigned to $80.9 \mathrm{ppm}$; this indicated that cyclodextrins had been successfully grafted onto chitosan.
Cellulose-chitosan gel was prepared from the solution of ferrocene-cellulose and cyclodextrin-chitosan at room temperature. The schematic diagram of the binding of cellulose and chitosan by an intermolecular inclusion interaction was shown in Figure 4 . The gel based on $\beta$-CD-chitosan and Fc-cellulose was formed under mild conditions which can engender autonomous healing between cut surfaces after 24 hours (Figure 5). To clarify the intermolecular inclusion interaction between the $\beta$-CD and Fc groups on cellulose and chitosan, a competitive guest molecule was coated onto the cut surfaces. Adamantane acid was used as a competitive guest, because the association constant for $\beta$-CD $\left(K_{a}=35 \times\right.$ $10^{3} \mathrm{M}^{-1}$ ) is higher than that of Fc. A $\beta$-CD-chitosan/Fccellulose gel was cut in half, and the cut surfaces were coated with a solution of adamantine acid ( $3 \mathrm{Mm})$. After $24 \mathrm{~h}$, healing was not observed. These results indicated the formation of an inclusion complex between the $\beta$-CD unit of $\beta$-CDchitosan and the Fc unit of Fc-cellulose. The compressive strength (Instron 3365 Universal Testing Machine (Norwood, MA, USA)) of Fc-cellulose/ $\beta$-CD-chitosan hydrogel (3 wt $\%$ ) without cracking was $4.70 \mathrm{kPa}$, and the compressive strength 
of the sample healed after standing for $24 \mathrm{~h}$ was $3.42 \mathrm{kPa}$. Thereafter, the compressive strength of the healed gel can recover $72.77 \%$ of its original compressive strength.

\section{Conclusion}

$\beta$-CD-chitosan/Fc-cellulose gel was prepared at room temperature, the $\beta$-CD unit of the $\beta$-CD-chitosan and the $\mathrm{Fc}$ unit of the Fc-cellulose can form inclusion complexes. The cellulose and chitosan can bind by intermolecular inclusion interaction. This research reports the resulting self-healing properties arising from host-guest interactions. The healed gel can recover $72.77 \%$ of its original compressive strength. The $\beta$-CD-chitosan/Fc-cellulose gel hydrogels have a wide potential for industrial applications including medicine, textiles, sports, cosmetics, and hygiene product manufacture.

\section{Conflict of Interests}

The authors declare that there is no conflict of interests regarding the publication of this paper.

\section{Acknowledgment}

This paper is supported by the Fundamental Research Funds for the Central Universities.

\section{References}

[1] R. Shepherd, S. Reader, and A. Falshaw, "Chitosan functional properties," Glycoconjugate Journal, vol. 14, no. 4, pp. 535-542, 1997.

[2] M. Rinaudo, "Chitin and chitosan: properties and applications," Progress in Polymer Science, vol. 31, no. 7, pp. 603-632, 2006.

[3] S. Duri and C. D. Tran, "Supramolecular composite materials from cellulose, chitosan, and cyclodextrin: facile preparation and their selective inclusion complex formation with endocrine disruptors," Langmuir, vol. 29, no. 16, pp. 5037-5049, 2013.

[4] Z. Liu, H. Wang, C. Liu et al., "Magnetic cellulose-chitosan hydrogels prepared from ionic liquids as reusable adsorbent for removal of heavy metal ions," Chemical Communications, vol. 48, no. 59, pp. 7350-7352, 2012.

[5] N. Li and R. B. Bai, "Copper adsorption on chitosan-cellulose hydrogel beads: behaviors and mechanisms," Separation and Purification Technology, vol. 42, no. 3, pp. 237-247, 2005.

[6] C. D. Tran, S. Duri, A. Delneri, and M. Franko, "Chitosancellulose composite materials: preparation, characterization and application for removal of microcystin," Journal of Hazardous Materials, vol. 252-253, pp. 355-366, 2013.

[7] M. M. Naim and H. E. M. Abdel Razek, "Chelation and permeation of heavy metals using affinity membranes from cellulose acetate-chitosan blends," Desalination and Water Treatment, vol. 51, no. 1-3, pp. 644-657, 2013.

[8] W. Xiao, T. Wu, J. Peng et al., "Preparation, structure, and properties of chitosan/cellulose/multiwalled carbon nanotube composite membranes and fibers," Journal of Applied Polymer Science, vol. 128, no. 2, pp. 1193-1199, 2013.

[9] B. Ma, M. Zhang, C. He, and J. Sun, "New binary ionic liquid system for the preparation of chitosan/cellulose composite fibers," Carbohydrate Polymers, vol. 88, no. 1, pp. 347-351, 2012.
[10] S. Zhang, W. Liu, J. Liang et al., "Buildup mechanism of carboxymethyl cellulose and chitosan self-assembled films," Cellulose, vol. 20, no. 3, pp. 1135-1143, 2013.

[11] F. Li, P. Biagioni, M. Finazzi, S. Tavazzi, and L. Piergiovanni, "Tunable green oxygen barrier through layer-by-layer selfassembly of chitosan and cellulose nanocrystals," Carbohydrate Polymers, vol. 92, no. 2, pp. 2128-2134, 2013.

[12] C. Stefanescu, W. H. Daly, and I. I. Negulescu, "Biocomposite films prepared from ionic liquid solutions of chitosan and cellulose," Carbohydrate Polymers, vol. 87, no. 1, pp. 435-443, 2012.

[13] W.-C. Lin, C.-C. Lien, H.-J. Yeh, C.-M. Yu, and S.-H. Hsu, "Bacterial cellulose and bacterial cellulose-chitosan membranes for wound dressing applications," Carbohydrate Polymers, vol. 94, no. 1, pp. 603-611, 2013.

[14] Y.-B. Wu, S.-H. Yu, F.-L. Mi et al., "Preparation and characterization on mechanical and antibacterial properties of chitsoan/cellulose blends," Carbohydrate Polymers, vol. 57, no. 4, pp. 435-440, 2004.

[15] S. Lin, L. H. Chen, L. L. Huang et al., "Preparation and characterization of chitosan/cellulose blend films using $\mathrm{ZnCl}_{2} \cdot 3 \mathrm{H}_{2} \mathrm{O}$ as a solvent," Bioresources, vol. 7, no. 4, pp. 5488-5499, 2012.

[16] J. Duan, Y. Wang, Y. Wang, and X. Xiong, "Preparation and characterization of cellulose-coated chitosan beads with improved strength and acid resistivity," Journal of Applied Polymer Science, vol. 126, no. 1, pp. E173-E179, 2012.

[17] S.-H. Yu, H.-Y. Hsieh, J.-C. Pang et al., "Active films from watersoluble chitosan/cellulose composites incorporating releasable caffeic acid for inhibition of lipid oxidation in fish oil emulsions," Food Hydrocolloids, vol. 32, no. 1, pp. 9-19, 2013.

[18] H. Feng, L. Zhang, and C. Zhu, "Genipin crosslinked ethyl cellulose-chitosan complex microspheres for anti-tuberculosis delivery," Colloids and Surfaces B: Biointerfaces, vol.103, pp. 530537, 2013.

[19] E. P. Azevedo, R. Raghavan, M. L. Raghavan, and V. Kumar, "Mechanical properties of cellulose: chitosan blends for potential use as a coronary artery bypass graft," Journal of Biomaterials Science: Polymer, vol. 24, no. 3, pp. 239-252, 2013.

[20] Z. Liu, H. Wang, B. Li et al., "Biocompatible magnetic cellulosechitosan hybrid gel microspheres reconstituted from ionic liquids for enzyme immobilization," Journal of Materials Chemistry, vol. 22, no. 30, pp. 15085-15091, 2012.

[21] Y. G. Baklagina, S. V. Kononova, V. A. Petrova et al., "Study of polyelectrolyte complexes of chitosan and sulfoethyl cellulose," Crystallography Reports, vol. 58, no. 2, pp. 287-294, 2013.

[22] Z. Su, Y. Yu, C. Liang, L. Li, and S. Yu, "Properties of chitosan-immobilized cellulase in ionic liquid," Biotechnology and Applied Biochemistry, vol. 60, no. 2, pp. 231-235, 2013.

[23] U. Vrabič Brodnjak and D. Gregor-Svetec, "Preparation and characterization of chitosan coatings onto regular cellulose fibers with ultrasound technique," Journal of Coatings Technology Research, vol. 10, no. 2, pp. 247-254, 2013.

[24] P. Peng, X. Cao, F. Peng, J. Bian, F. Xu, and R. Sun, "Binding cellulose and chitosan via click chemistry: synthesis, characterization, and formation of some hollow tubes," Journal of Polymer Science Part A: Polymer Chemistry, vol. 50, no. 24, pp. 5201-5210, 2012.

[25] J. P. de Mesquita, C. L. Donnici, I. F. Teixeira, and F. V. Pereira, "Bio-based nanocomposites obtained through covalent linkage between chitosan and cellulose nanocrystals," Carbohydrate Polymers, vol. 90, no. 1, pp. 210-217, 2012. 
[26] E. Kosecka-Judin, M. Wesolowski, and D. Paukszta, "Pattern recognition methods as supplementary techniques for identification of salicylamide-cyclodextrins inclusion complexes," Central European Journal of Chemistry, vol. 10, no. 5, pp. 15341546, 2012.

[27] C. Volobuef, C. M. Moraes, L. A. S. Nunes et al., "Sufentanil2-hydroxypropyl- $\beta$-cyclodextrin inclusion complex for pain treatment: physicochemical, cytotoxicity, and pharmacological evaluation," Journal of Pharmaceutical Sciences, vol. 101, no. 10, pp. 3698-3707, 2012.

[28] J. Duan, X. Zhang, J. Jiang et al., "The synthesis of a novel cellulose physical gel," Journal of Nanomaterials, vol. 2014, Article ID 312696, 7 pages, 2014.

[29] J. F. Duan, J. Jiang, C. Han, J. Yang, L. Liu, and J. Li, "The study of intermolecular inclusion in cellulose physical gels," BioResources, vol. 9, no. 3, pp. 4006-4013, 2014.

[30] J. Wan, Z. Hu, W. Chen, H. Chen, and Z. Yu, "Synthesis and application on enrichment of metal ions of cellulose fibre grafted $\beta$-cyclodextrin," Acta Polymerica Sinica, vol. 2004, no. 4, pp. 566-572, 2004. 

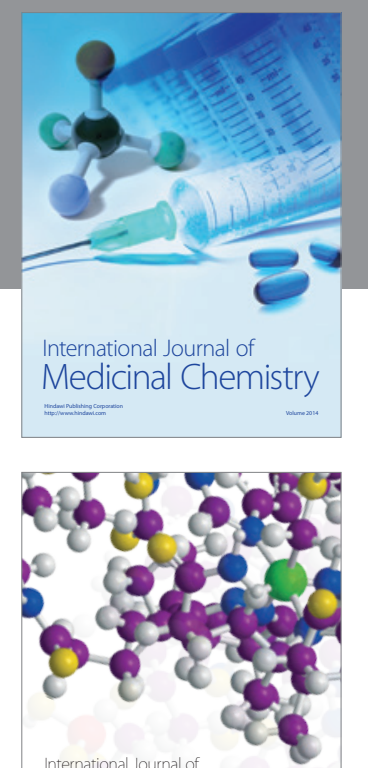

\section{Carbohydrate} Chemistry

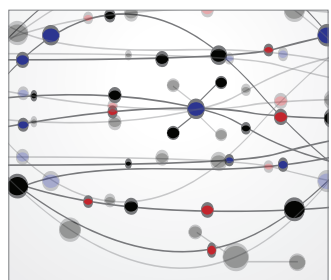

The Scientific World Journal
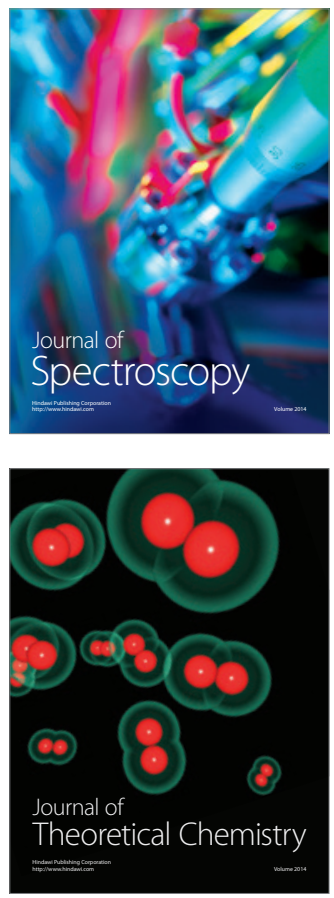


Submit your manuscripts at

http://www.hindawi.com

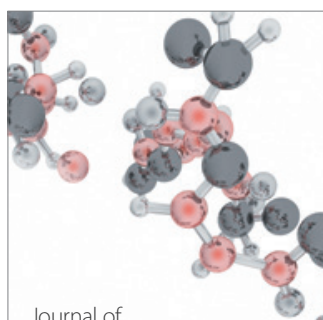

Analytical Methods

in Chemistry

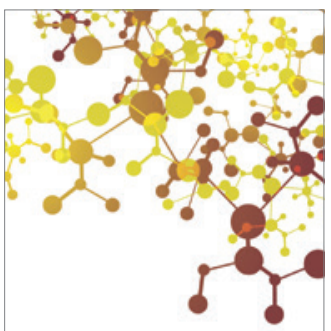

Journal of

Applied Chemistry

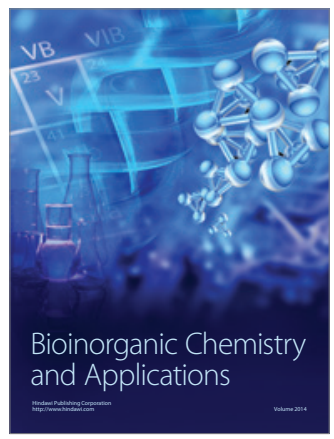

Inorganic Chemistry
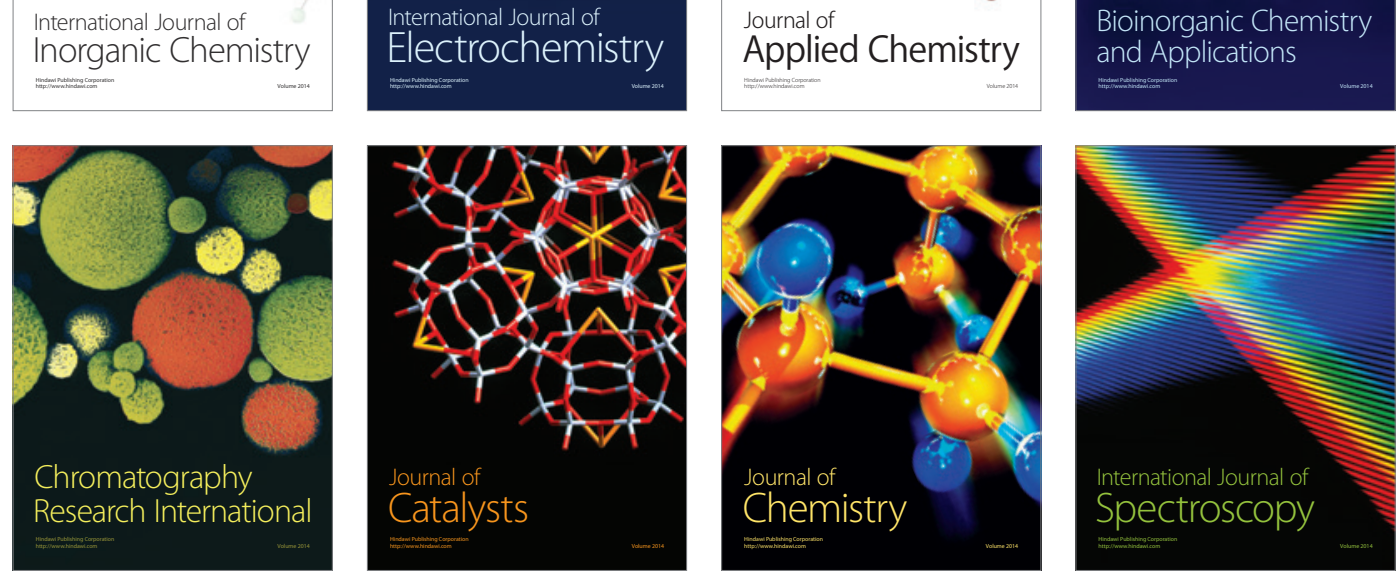